\title{
Paul OBERHOLZER (ed.), Diego Laínez (1512-1565) and his Generalate. Jesuit with Jewish Roots, Close Confidant of Ignatius of Loyola, Preeminent Theologian of the Council of Trent, Roma, Institutum Historicum Societatis lesu, 2015. 1074 pp. ISBN: 978- 88-7041-376-2
}

Dentro de la prolífica producción impresa de la Compañía de Jesús a lo largo de la historia, unas personalidades han tenido un mayor peso que otras. La figura de Diego Laínez, segundo general de la Orden y primer sucesor de Ignacio de Loyola, ha sufrido un interés cambiante dentro de los estudios e investigaciones sobre la propia Compañía. Este vaivén ha venido producido, entre otras cosas, por el carácter converso de Laínez, que ha provocado que haya sido menos estudiado que otros jesuitas contemporáneos como Francisco de Borja, por no mencionar al mismo san Ignacio. Ello, a pesar de su notable influjo en las sesiones del concilio de Trento y de gobernar la orden ignaciana en sus primeras décadas, manteniendo, e incluso aumentando, el impulso fundacional que había tenido la Compañía en sus primeros años de existencia. Aunque no le sucedió lo mismo que a su compañero y amigo Alfonso Salmerón, que cayó más en el olvido para la historiografía, la producción escrita acerca de la vida de Diego Laínez ha estado, en cierta manera, sometida por los antecedentes familiares judaizantes. El libro que presentamos en estas páginas trata de superar ese estigma y analiza en profundidad y desde diversos puntos de vista la vida de una de las grandes personalidades teológicas de mediados del siglo XVI, que participó de las grandes disputas doctrinales con los teólogos protestantes y que contribuyó al crecimiento y extensión de una de las órdenes religiosas más influyentes $\mathrm{y}$, al mismo tiempo, polémicas de la historia.

A pesar de que el libro esté publicado en 2015, su gestación se inició un lustro antes con la idea inicial de que incluso pudiera formar parte de las celebraciones en 2012 por el quinto centenario del nacimiento del religioso en Almazán. Sin embargo, su publicación se retrasó por diversas circunstancias relacionadas con el periplo vital del autor principal y su trayectoria dentro de la Compañía de Jesús, que permitió un valioso tiempo de reflexión y trabajo que sirvió para pulir el texto con algunas incorporaciones. Así lo expresa el editor, Paul Oberholzer, actualmente profesor de la Universidad Gregoriana, que inició la empresa de publicar un libro acerca del segundo general jesuita mientras dirigía el Institutum Historicum Societatis lesu en Roma. Junto a él, aparecen destacados investigadores de diversas nacionalidades e idiomas, como Enrique García Hernán, Thomas McCoog o Flavio Rurale.

El libro tiene una estructura un tanto diferente de lo que canónicamente puede entenderse como un libro de homenaje o que pretenda ser una biografía colectiva. Ahí puede estar uno de sus valores, puesto que, de esta manera, la obra aporta más información que 
una serie de textos organizados cronológicamente y dedicados única y específicamente a la vida de Laínez. A través de una división en siete partes, en el libro dirigido por Oberholzer nos encontramos con artículos monográficos sobre aspectos concretos de la vida del jesuita soriano, pero, sobre todo, con otros de carácter más general sobre la época en la que vivió y los asuntos en los que se vio inmerso. Junto a ellos, algunas de las secciones se concluyen con interesantes ediciones de fuentes inéditas, especialmente procedentes del Archivum Romanum Societatis lesu (ARSI).

La primera sección del libro, "Introductory Reflexions", está compuesta de dos artículos que son fruto de las investigaciones que el propio Oberholzer realizó con posterioridad a la gestación original del proyecto, durante su tercera probación en México. En ellos, reflexiona en torno al proceso de conformación de la Compañía de Jesús y su evolución en las décadas siguientes a 1540, que culminó con la primera reducción paraguaya, fundada en 1609.

En la segunda parte, "Personality and Ministry", nos encontramos con la razón por la que la obra no es una biografía al uso, ya que remite a las redactadas por Mario Scaduto para el Diccionario histórico de la Compañía de Jesús (2001) y el volumen 118 (1990) de Archivum Historicum Societatis lesu. Es destacable en esta sección la completa cronología firmada por Javier Cía Blasco y el amplísimo capítulo que firma el propio Oberholzer, en el que reflexiona en torno a los principales hitos de la vida de Laínez y el modo en el que historiográficamente han sido atendidos. En tercer lugar nos encontramos con un interesante análisis de Sibylle Appuhn-Radtke sobre la imagen lainiana a través de sus diferentes retratos.

La tercera parte, "Political and Social Milieu", presenta algunos aspectos del ambiente general en el que se encontró la Compañía de Jesús, como el clima anticonverso y el trabajo que desarrollaron sus religiosos en Italia, especialmente en el entorno papal romano. Atendiendo a la temática de estos capítulos y de los de la siguiente sección, considero que habría sido interesante integrarlos todos (o algunos) en un mismo bloque, puesto que en la cuarta parte, "Works and Networks", nos encontramos con artículos en torno al carácter judeoconverso de algunos de los primeros jesuitas o las misiones que desarrollaron en Gran Bretaña, Irlanda y Holanda. Junto a estos asuntos, en esta sección del libro también se analizan las relaciones que Diego Laínez mantuvo con diversas personalidades de su tiempo, pertenecientes a los ámbitos de la política, la espiritualidad y la propia Compañía de Jesús, como Felipe II, Carlos Borromeo, Francisco de Borja y Antonio Possevino.

La quinta parte, "Catholic Reform", se fija en diversas cuestiones acerca de la pastoral y la teología de mediados del siglo XVI, especialmente el Concilio de Trento, en cuyas sesiones Diego Laínez tuvo un importante peso. En este punto, llegamos a la misma conclusión que exponíamos en el anterior párrafo, puesto que, aunque hay intervenciones sobre el Concilio y la reforma capuchina, también se añade un capítulo sobre la concepción del arte en la Compañía, firmado por Lydia Salviucci Insolera, que podía haberse introducido en el siguiente bloque, dedicado a temas culturales y educativos. De este modo, se podrían incluir con los de la sexta parte, "Cultura y Educación", que está enfocada a mostrar diversos temas relativos al arte, la literatura, educación y el ambiente intelectual, como los colegios, el teatro que se desarrollaba en ellos, el catecismo de Laínez y su uso en Alemania, el arte y los colegios Romano y Germánico.

Por último, la obra presenta la evolución de la Compañía de Jesús fuera de Europa, especialmente el área africana y Extremo Oriente (China e India). En este sentido, coincidimos con Oberholzer en que habría sido interesante incluir algún texto relativo a las fundaciones japonesas y brasileñas, aunque en este último caso lo extenderíamos en general al continente americano, al que se hacen muy pocas referencias. 
La obra concluye con una serie de apéndices finales. El primero presenta y localiza en el tiempo la participación de diferentes jesuitas en el Concilio de Trento. El segundo aporta unos breves apuntes biográficos de todos los jesuitas citados a lo largo de la obra. En tercer lugar, después de las abreviaturas y unas breves biografías de los diferentes autores que han participado en la confección del libro, se incluye una extensa bibliografía final en la que aparecen conjuntamente todos los materiales citados por los diferentes autores (manuscritos, impresos, bibliografía). No obstante, esta bibliografía no hace más que complementar el análisis realizado por Robert Danieluk a la investigación en torno a Laínez y la extensa bibliografía con la que concluye la segunda parte.

A pesar del enorme interés que encierra la obra que estamos presentando y del vacío que llena en torno a la figura del padre Laínez, hay cuestiones que podrían haberse mejorado. Entre los debes de la obra se encontrarían aquellos que el propio Oberholzer señala haciendo un loable esfuerzo de modestia y de honradez, como la falta de algunos temas que considera que deberían haberse tratado en sus páginas, pero que, por no haber localizado "autores competentes y disponibles" que pudieran afrontar con suficiencia esas temáticas, se ha preferido dejar en blanco a atenderlos de manera vaga. En este sentido, junto a las misiones japonesas y brasileñas, se señala la labor como provincial en Italia y la percepción de Laínez en fuentes documentales fuera del ambiente jesuítico o de sus simpatizantes. No obstante, estas lagunas no impiden que tanto el editor como los diferentes autores y colaboradores que le han ayudado en la confección del libro hayan conseguido el objetivo de presentar un interesante análisis de la vida y contexto que rodeó al padre Laínez, sirviendo de estímulo y empuje para la investigación acerca de su época y figura.

David Martín López

Universidad de Castilla-La Mancha 